\title{
Teenage Pregnancy: Time for Change and Action
}

\author{
Chelsea Campbell ${ }^{1}$, Kruti Lehenbauer ${ }^{2}$ \\ ${ }^{1}$ Doctoral Student, University of the Incarnate Word, San Antonio, USA, chcampbe@student.uiwtx.edu \\ ${ }^{2}$ Associate Professor of Business, University of the IncarnateWord, San Antonio, USA, lehenbau@uiwtx.edu
}

\begin{abstract}
Although the teenage pregnancy rate in the United States has declined over the years, it is still higher than the teenage pregnancy rates in other industrialized countries. This paper attempts to identify the types of changes that have occurred between 1994 and 2017 by comparing the results of a 1996 study by Ventura, Martin, Matthews \& Clarke with the results obtained using the 2017 National Natality Dataset obtained from the Center of Disease Control via the National Center of Health Statistics. The new data from 2017 demonstrates that the proportions of teenage births have gone down over the past few years, and that the racial/ethnicity component of teenage childbearing is also showing a narrowing trend. Even though we recognize the downward trend in teenage pregnancy, the concerns regarding the long-term socioeconomic outcomes arising from teenage births are still at large. We conduct a quantitative Logit analysis to identify what factors increase the probability of teenage motherhood in the United States and also conduct a short analysis of relevant existing public policies to provide recommendations for improvements that could potentially reduce the risk factors of teenage pregnancy in the United States.
\end{abstract}

KEYWORDS: Teenage childbearing, birth rates, socioeconomic outcomes

\section{Introduction}

Being a teenage mother has a strong social focus and has impacts on the labor force in the economy. There has been a focus on teenage childbearing since the 1970s, since the social challenges can have an impact on the mother and child and lead to poor socioeconomic outcomes. Within the United States there has been a steady decline in the teenage pregnancy rate, however the rate is still higher than industrialized countries in the world. A brief overview of existing literature will allow us to separate the literature into 3 sections - socioeconomic factors of birth outcomes, teenage birth rate changes over time and racial/ethical component of teenage childbearing.

The primary research question for the study is to detect and confirm the variables that contribute to increased risk of teenage childbearing in the United States by conducting a statistical analysis of all births for the year 2017 obtained from the National Center for Health Statistics (2018). We aim to identify the factors that impact birth outcomes and compare the outcomes for teenage verses non-teenage mothers. Thus, we propose to test two hypotheses in this study:

1. Are the maternal characteristics, history, and choices/factors consistently significant for the teenage versus non-teenage mothers? How do they differ?

2. Which factors determine the probability of teenage childbearing in the United States? Can any of these be addressed using policy instruments to lower the risk of teenage childbearing?

There will be a concise review of the existing literature, with primary focus on the socioeconomic factors that contribute to better birth outcome such as birth weight and longer gestation. Within the literature review, we will explore the identified variables that contribute to an increased risk of teenage childbearing. Thereafter, we discuss the dataset and the quantitative model before offering the results and conclusions that aim to lower the risk of teenage childbearing in the United States.

\section{Literature Review}

\section{A. Socioeconomic Factors of Birth Outcomes}

Even with advances in medical care for pregnancy and deliveries and implementation of programs to allow care for the impoverished population, the proportion of births that are low birth weight has only changed a little over the last 30 years, and the difference in the index between black and white populations have not lessened (Parnell, Sargent, Thompson, Duhe, Valois, \& Kember, 1996). Prior research shows that a woman's age impacts the birth weight of a baby. Teenage girls are two times more likely to deliver a low weight infant than adult women (Ventura, Martin, Matthews, \& Clarke 
1996). A woman who is older than 45 years old will have the same risk of having a low birth weight baby as a teenager who is younger than 15 years old.

Table 1. Comparing Results from 1994 and 2017 for Percent of Low Birth Weight and Live Births by Age of Mother: USA

\begin{tabular}{|c|c|c|c|}
\hline \multicolumn{4}{|c|}{$\begin{array}{l}\text { Table } 1 \\
\text { Number and Percent Low Birth Weight } \\
\text { and Live Births, by Age of Mother: United States } 1994\end{array}$} \\
\hline $\begin{array}{l}\text { Age of } \\
\text { Mother }\end{array}$ & $\begin{array}{l}\text { Number } \\
\text { of Births } \\
<2,500 \mathrm{~g}\end{array}$ & $\begin{array}{l}\text { Total Live } \\
\text { Births }\end{array}$ & $\begin{array}{l}\text { Percent } \\
<2,500 \mathrm{~g}\end{array}$ \\
\hline$<15$ & 1,766 & 12,901 & 13.7 \\
\hline 15 & 3,527 & 30,742 & 11.5 \\
\hline 16 & 6,502 & 63,125 & 10.3 \\
\hline 17 & 9,685 & 101,302 & 9.6 \\
\hline 18 & 12,526 & 137,547 & 9.1 \\
\hline 19 & 14,851 & 172,772 & 8.6 \\
\hline $20 \cdot 24$ & 72,565 & $1,00 t, 418$ & 7.3 \\
\hline $25 \cdot 29$ & 69,850 & $1,088,845$ & 6.4 \\
\hline $30-34$ & 60,645 & 906,498 & 6.7 \\
\hline 35.39 & 29,447 & 371,608 & 7.9 \\
\hline 40.44 & 5,922 & 63,502 & 9.3 \\
\hline 45.49 & 321 & 2,507 & 12.8 \\
\hline All Ages & 287,607 & $3,952,767$ & 7.3 \\
\hline
\end{tabular}

\begin{tabular}{|c|c|c|c|}
\hline \multicolumn{4}{|c|}{ Table 1} \\
\hline \multicolumn{4}{|c|}{$\begin{array}{l}\text { Number and Percent Low Birth Weight and Live } \\
\text { Births, by Age of Mother: United States } 2017\end{array}$} \\
\hline $\begin{array}{r}\text { Age of } \\
\text { Mother }\end{array}$ & $\begin{array}{c}\text { Number of } \\
\text { Births } \\
<2,500 \mathrm{~g} \\
\end{array}$ & $\begin{array}{l}\text { Total Live } \\
\text { Births }\end{array}$ & $\begin{array}{l}\text { Percent } \\
<2,500 \mathrm{~g}\end{array}$ \\
\hline$<15$ & 225 & 1,921 & 11.7 \\
\hline 15 & 616 & 5,601 & 11.0 \\
\hline 16 & 1,450 & 14,401 & 10.1 \\
\hline 17 & 2,877 & 28,664 & 10.0 \\
\hline 18 & 5,397 & 54,321 & 9.9 \\
\hline 19 & 8,899 & 91,774 & 9.7 \\
\hline $20-24$ & 65,763 & 766,112 & 8.6 \\
\hline $25-29$ & 87,035 & $1,126,355$ & 7.7 \\
\hline $30-34$ & 83,834 & $1,094,790$ & 7.7 \\
\hline $35-39$ & 48,992 & 556,241 & 8.8 \\
\hline $40-44$ & 12,591 & 115,162 & 10.9 \\
\hline $45-49$ & 1,510 & 8,551 & 17.7 \\
\hline$>49$ & 238 & 861 & 27.6 \\
\hline All ages & 319,427 & $3,864,754$ & 8.3 \\
\hline
\end{tabular}

\section{B. Racial/Ethical Component}

Sources: Ventura (1994); NCHS (2018)

As indicated in the research by (Roth, Hendrickson, Schilling, \& Stowell 1998), "7.3\% of all women who gave birth in the United States delivered a low birth weight infant in 1994, it obscured the fact that the low birth weight percentage rate for black women was more than double that for white women. "East Asian women have the lowest rate of preterm births, as well as Hispanic women" (Goldenberg \& Culhane 2007). Women that are from South Asia and in particular the Indian subcontinent have a high rate of low birth weight (Goldenberg \& Culhane 2007). Low birth weight creates a higher challenge for caregivers being able to provide appropriate health care to the infants (Klerman 1993). Throughout the literature, what stands out in multiple studies is that black women have a high rate of preterm and low birth weight and it remains unexplainable.

In addition to race, the income of the family has a correlation with birth outcomes (Kaplan, Pamuk, Lynch, Cohen, \& Balfour 1996). It is said that teenagers who become pregnant are poorer than any other age group on women who have a child in the United States. "Recent estimates place $40 \%$ of US adolescent low-income population accounts for six out of seven teenage births" (Males 1995). Most of the teenage mothers are not married and do not receive financial support from the child's father. These mothers are more likely to have parents who have low income, low educational attainment and be members of a racial minority group (Roth, Hendrickson, Schilling, \& Stowell 1998).

The geographical location of the mother has also shown in prior research to have an impact on the birth weight of infants. Infants that are born in India will be on average 6 pounds, 6 ounces; in Sweden the average infant is 7 pounds, 11 ounces (National Center for Health Statistics (NCHS) 2018). Within urban areas there is a high concentration on minority teenager where teenage mothers drink, smoke and use drugs less than the white suburban and rural counterparts (Scholl, Hediger, \& Belsky 1993). Thus, if a woman is giving birth in the United States but is primarily residing in another country, the birth outcomes of the infant are likely to be different than for women residing in the United States. 
In summary, women who are poor or black have twice the preterm birth rate and higher likelihood of growth restrictions than most other women (Goldenberg \& Culhane 2007). Based on the literature, the main socioeconomic variables that impact the birth weight of an infant are age of mother, age of father, race/ethnicity of mother and residency status of mother.

\section{Teenage Birth Rates}

The teenage birth rate has declined throughout the last century (Kost, Maddow-Zimet, \& Arpaia 2017). The way in which the teenage birth rate is calculated is by taking the number of pregnancies per 1,000 women between the ages of 15-19. While looking at the teenage birthrate over the last 25 years there has been a drastic decrease by 63 percent, from 117.6 pregnancies per 1,000 women with the age range of 15-19 to 43.4 in 2013 (most recent data available) (Kost, Maddow-Zimet, \& Arpaia 2017). Teenage births made up for 5.3 percent of births in 2016, where 89 percent of those births occurred outside of marriage (Martin et al. 2018). In 2016, the teen birth rate decreased by 9 percent from 2015. In 2015, the teen birth rate was 22.3, which was down 67 percent from 1991 when there was an all-time high of 61.8 percent (Martin et al. 2018). Based on prior research, the decrease in the teenage birth rate is due to increased awareness of necessary birth control used by teenagers and teenagers waiting to have sexual intercourse (Kost, Maddow-Zimet, \& Arpaia 2017; Santelli et al. 2007). Table 1, which includes similar information from our dataset indicates that the teen birth rate has declined even further to $5.1 \%$ in 2017.

Based on prior research, in 2013, approximately 61 percent of the pregnancies to 15 to 19 year-olds in the U.S. resulted in a live birth; 15 percent of pregnancies resulted in miscarriage; and 25 percent of pregnancies were ended in an abortion. The abortion rate amongst teenagers is reported at an all-time low since abortion was made legal in 1973 (Kost, Maddow-Zimet, \& Arpaia 2017). There was a spike in abortion in 1988, and there has been a 76 percent decrease since that initial spike (Kost, Maddow-Zimet, \& Arpaia 2017). Between 1988 and 2005 the pregnancy rate for teens declined in all states. There was a spike from 2005 to 2008 where there was a decrease in the teen birth rate in 18 states, 5 states stayed at the same birth rate and 27 states saw an increase. From 2008 to 2013 there was yet another decrease in the teenage birth rate in all states (Kost, MaddowZimet, \& Arpaia 2017). Thus, the number of previous live births and previous terminations of pregnancy do impact the probability of a teenager becoming a mother.

Teenage birth rates vary by age, race, ethnic group, and region of the country. While exploring age within the teenage child birthing, 74 percent of those births were for teens 18 to 19 years old in 2016 (Martin et al. 2018). Another factor that attributes to higher birth rates is ethnicity, the birth rates in Hispanic and black teenagers were higher than in white teenagers. In 2016, the birth rates for Hispanics were the highest at 31.9 births per 1,000 teenage females, followed by black teenage females (29.3) and finally by white teenage females (14.3) (Martin et al. 2018). In our study, we find that while white teenage mothers constitute $3.63 \%$ of all births to white mothers in the Untied States in 2017, the corresponding rates for black and Hispanic mothers are $7.24 \%$ and $7.78 \%$ (see Methodology and Data section for more details).

The estimation from a study in 2013 shows that $8 \%$ of white teenage females will give birth by the time they are 20, with the corresponding numbers being $16 \%$ and $17 \%$ for black and Hispanic teenage females (Office of Adolescent Health 2017). The birth rate for Hispanic teenagers is currently the highest, however it also shows the highest decline rate by $58 \%$, compared to a decline of 53\% for black and 47\% for white teenagers (Martin et al. 2018). A quantitative study by Kost, Maddow-Zimet, \& Arpaia (2017) explains that birth rates for teenage black women were consistently higher than Hispanics and white women since 1991, where black women had a higher birth rate by $36 \%$. This began to change in 2004 , when the birth rate for Hispanic teenage women grew.

\section{Methodology and Data}

The primary dependent variable in this study is the birth weight of the infant $(d b w t)$ and an Ordinary Least Squares (OLS) regression analysis approach is used to identify the significant 
factors. Based on the literature, the main socioeconomic variables that impact the birth weight of an infant are age of mother (mager), age of father (fath_age), race/ethnicity of mother (mwhite, mblack, mhisp, m_otherrace), race/ethnicity of father (fwhite, fblack, fhisp, f_otherrace), educational attainment of mother $($ meduc), educational attainment of father $(f e d u c)$, previous pregnancies (priorlive, priordead, priorterm), maternal smoking prior to pregnancy (smoker, cig_0), height of mother ( $m_{-} h t$ in $)$, pre-pregnancy weight ( $\left.p w g t+r\right)$ and body mass index (bmi) of mother, presence of risk or infection factors (no_infec, no_risks), ability to pay for care (pay_rec), receiving prenatal care (precare, previs), residency status of mother (restates), marital status (dmar), and the biological variables are the length of gestation (combgest) and sex (sex_baby) of the infant. Even though income is a significant contributor to a child's birthweight as demonstrated in the literature, our study is omitting this variable because the National Natality Dataset (National Center for Health Statistics (NCHS), 2018) used for our quantitative model does not provide this information publicly. Thus, our base model, Model 1 is as follows:

$$
\begin{aligned}
\text { dbwt }=\beta_{0}+ & \beta_{1} \text { combgest }+\beta_{2} \text { sex_baby }+\beta_{3} \text { foreigner }+\beta_{4} \text { dmar }+\beta_{5} \text { mager }+\beta_{6} \text { mwhite } \\
& +\beta_{7} \text { mblack }+\beta_{8} \text { mhisp }+\beta_{9} \text { meduc }+\beta_{10} \text { fager }+\beta_{11} \text { fwhite }+\beta_{12} \text { fblack } \\
& +\beta_{13} \text { fhisp }+\beta_{14} \text { feduc }+\beta_{15} m_{-} \text {ht_in }+\beta_{16} \text { bmi }+\beta_{17} \text { pwgt_r }+\beta_{18} \text { priorlive } \\
& +\beta_{19} \text { priordead }+\beta_{20} \text { priorterm }+\beta_{21} \text { precare }+\beta_{22} \text { previsits }+\beta_{23} \text { smoker } \\
& +\beta_{24} \text { cig_ } 0+\beta_{25} \text { no_risks }+\beta_{26} \text { no_infect }+\beta_{27} \text { pay_rec }+\beta_{28} \text { wic_yes } \\
& +\beta_{29} \text { teenmom }+\beta_{30} \text { teendad }+\varepsilon
\end{aligned}
$$

Since the focus of this paper is on the risks of teenage pregnancy, we estimate two separate models, Model 2 and Model 3, to compare the birth weight outcomes between non-teenage and teenage mothers along with Model 1 . We remove the teenmom variable in these models since we are estimating these separately.

Estimating the probability of being a teenage mother is the next step in our methodology. We can calculate odds ratios for relevant by using a logistical model to show if some factors add to the increased odds of becoming a teenage mother, with special focus on race and ethnicity. Thus, we estimate Model 4 to calculate the log odds of teenmom with probability $p$ to non-teen mother with probability of $(1-p)$ within our sample, by using a logistical model as follows:

$$
\begin{aligned}
\log \left(\frac{p}{1-p}\right)= & \beta_{0}+\beta_{1} \text { dmar }+\beta_{2} \text { meduc }+\beta_{3} \text { teendad }+\beta_{4} \text { fwhite }+\beta_{5} \text { fblack }+\beta_{6} \text { fhisp } \\
& +\beta_{7} \text { feduc }+\beta_{8} \text { priorterm }+\beta_{9} \text { smoker }+\beta_{10} \text { no_risks }+\beta_{11} \text { no_infec }+\varepsilon
\end{aligned}
$$

To separate out the effects by race, we estimate this model in three different parts $4 \mathrm{a}, 4 \mathrm{~b}$, and $4 \mathrm{c}$ to represent white mothers, black mothers, and Hispanic mothers, respectively.

Data for this study is obtained from the Center for Disease Control (CDC) that maintains natality datasets for public use (National Center for Health Statistics (NCHS) 2018). The birth records for the year 2017 are used to represent the population of all births in the USA in the year 2017. About 3.8 million babies were born in the United States in 2017 and all of them have been included in this dataset. Based on the data, the racial and ethnicity-based distribution of teenage versus non-teenage pregnancies are shown in Table 2.

As we can see from Table 2, the incidence of teenage pregnancy is extremely high among non-Hispanic black and Hispanic mothers. For the sake of convenience, we will be merging nonHispanic AIAN, non-Hispanic Asian, non-Hispanic NHOPI, non-Hispanic multi-race, and racial origin unknown mothers into one category of "other races," even though their characteristics are markedly different. Table 3 presents the Summary Statistics for the primary variables used in this analysis, and we will begin with discussing these in the Results section. Within the variables mentioned in Table 3, it is hypothesized that there will be a statistically significant relationship between the independent variables and the dependent variables and that these variables are indeed the prominent determinants of birth weight outcomes. This study tries to fill the gap of including a 
large base of variables and utilizes recent data to understand whether the variables listed above have any statistically significant impact in birth weight of infants. We also hypothesize that there are some key factors within these variables that will contribute to the increased probability of a teenage pregnancy based upon the history, characteristics, and choices of mothers.

Table 2. Distribution of Births to Teen and Non-teen Mothers based on Race and Ethnicity in 2017

\begin{tabular}{|r|rc|rc|r|}
\hline & \multicolumn{2}{|c|}{ Non-Teen Moms } & \multicolumn{2}{c|}{ Teen Moms } & \\
Race/Ethnicity of Mother & Number & Percentage & Number & Percentage & \multicolumn{1}{c|}{ Total } \\
\hline non-Hispanic White & $1,921,051$ & $96.37 \%$ & 72,261 & $3.63 \%$ & $1,993,312$ \\
non-Hispanic Black & 520,662 & $92.76 \%$ & 40,635 & $7.24 \%$ & 561,297 \\
Hispanic & 835,501 & $92.22 \%$ & 70,497 & $7.78 \%$ & 905,998 \\
non-Hispanic AIAN & 27,049 & $90.26 \%$ & 2,918 & $9.74 \%$ & 29,967 \\
non-Hispanic Asian & 247,879 & $99.30 \%$ & 1,737 & $0.70 \%$ & 249,616 \\
non-Hispanic NHOPI & 8,943 & $94.78 \%$ & 493 & $5.22 \%$ & 9,436 \\
non-Hispanic multi-race & 75,389 & $91.43 \%$ & 7,066 & $8.57 \%$ & 82,455 \\
Origin unknown & 31,598 & $96.71 \%$ & 1,075 & $3.29 \%$ & 32,673 \\
\hline Total & $3,668,072$ & $94.91 \%$ & 196,682 & $5.09 \%$ & $3,864,754$ \\
\hline
\end{tabular}

Source: National Natality Data Set 2016-17, NCHS (2018)

\section{Results of Data Analysis}

For estimating our models, we have used STATA version 15.0. As we can see in Table 3, 51.6\% of the mothers in our sample are white, $14.5 \%$ are black, and $23.4 \%$ are Hispanic. Moreover, the average age of a mother in the United States in 2017 was 28.85 years and only $2 \%$ of the mothers were primarily residing in foreign countries, who were only present in the United States at the time of birth, resulting in a local birth.

The education variables for mother and father have been split into 9 categories, with 0 representing unknown level of education, 1 representing less than $8^{\text {th }}$ grade, 2 representing between $9^{\text {th }}$ and $12^{\text {th }}$ grade, 3 representing completion of high school diploma/GED, 4 representing some college credits, 5 representing Associate's Degree, 6 representing Bachelor's degree, 7 representing Master's degree, and 8 representing a Doctoral degree. The average education level in our data set is about 4.2 for mothers and 3.64 for fathers with standard deviations of 1.79 and 2.19 , respectively indicating that about $67 \%$ of the mothers have between $9^{\text {th }}$ and $12^{\text {th }}$ grade education on the lower end and a bachelor's degree on the higher end. A curious result from this dataset is that only about $60 \%$ of the mothers in the United States are married. The average number of prior living children to each mother who gave birth in the United States in 2017 is 1.135 and on an average each woman has had 0.42 prior pregnancy terminations. It is important to note that these terminations can be a result of natural or induced abortions, and therefore should not be taken in any other spirit.

$69 \%$ of the mothers in our sample showed that they did not have any risk factors and $97.3 \%$ reported no infections during pregnancy. On an average, women seek prenatal care in the third month of pregnancy and average about 11.3 visits during their pregnancy to seek prenatal care. About $37.6 \%$ of the women got Women with Infants and Children (WIC) assistance in the United States in 2017, indicating a heavy reliance on welfare in the country for child-rearing.

The dependent variables show that the average birth weight in 2017 was about 3262 grams (approximately $7.19 \mathrm{lbs}$ ) and the average pregnancy lasted about 38.6 weeks of gestation. $51.2 \%$ of the babies born in 2017 were males. As we have observed before, 5.1\% of the mothers in the United States were teenagers (between 12 and 19 years of age, inclusive), which raises the question of identifying what contributes to these teenage pregnancies. Table 4 shows the results of estimating Models 1, 2, and 3 with birthweight as the dependent variable and applying an OLS regression analysis approach.

There are about 30 variables that were included in this analysis. For the sake of precision, let us focus on some key variables with attention to the differences between Model 2 and Model 3 
results to identify if the impacts of these factors are different on teenage mothers or not. The birthweight of infant increases by about 125 grams for each additional week of gestation for nonteen mothers as compared to only 104 grams for teenage mothers. The sex of the baby does not affect birthweight of the baby in teenage mothers to the same extent as it does in non-teen mothers.

Table 3. Summary Statistics for Primary Variables Used in the Analysis

\begin{tabular}{|c|c|c|c|c|c|c|}
\hline Var Name & Variable Description & Obs & Mean & $\begin{array}{l}\text { Std. } \\
\text { Dev. }\end{array}$ & Min & Max \\
\hline \multicolumn{7}{|c|}{ Maternal Characteristics } \\
\hline teenmom & 1 if mother is a teenager, 0 otherwise & $3,864,754$ & 0.051 & 0.220 & 0 & 1 \\
\hline mager & Mother's Single Years of Age & $3,864,754$ & 28.847 & 5.815 & 12 & 50 \\
\hline mracehisp & Mother's Race/Hispanic Origin & $3,864,754$ & 2.869 & 2.507 & 0 & 7 \\
\hline foreigner & 1 if foreigner, 0 otherwise & $3,864,754$ & 0.020 & 0.150 & 0 & 1 \\
\hline dmar & Marital Status & $3,391,934$ & 0.599 & 0.490 & 0 & 1 \\
\hline meduc & Mother's Education & $3,864,754$ & 4.268 & 1.792 & 0 & 8 \\
\hline m_ht_in & Mother's Height in Total Inches 30-78 & $3,842,791$ & 64.129 & 2.837 & 30 & 78 \\
\hline bmi & Body Mass Index 13.0-69.9 & $3,767,370$ & 26.974 & 6.701 & 13 & 68.9 \\
\hline pwgt_r & Pre-pregnancy Weight in lbs. 075-375 & $3,778,180$ & 157.988 & 41.578 & 75 & 375 \\
\hline mhisp & 1 if only Hispanic origin, 0 otherwise & $3,864,754$ & 0.234 & 0.424 & 0 & 1 \\
\hline mblack & 1 if only Black origin, 0 otherwise & $3,864,754$ & 0.145 & 0.352 & 0 & 1 \\
\hline mwhite & 1 if only White origin, 0 otherwise & $3,864,754$ & 0.516 & 0.500 & 0 & 1 \\
\hline \multicolumn{7}{|c|}{ Paternal Characteristics } \\
\hline teendad & 1 if father is a teenager, 0 otherwise & $3,864,754$ & 0.017 & 0.131 & 0 & 1 \\
\hline fath_age & Father's Age & $3,864,753$ & 4.351 & 2.057 & 0 & 10 \\
\hline fwhite & 1 if only White origin, 0 otherwise & $3,864,754$ & 0.460 & 0.500 & 0 & 1 \\
\hline fblack & 1 if only Black origin, 0 otherwise & $3,864,754$ & 0.120 & 0.320 & 0 & 1 \\
\hline fhisp & 1 if only Hispanic origin, 0 otherwise & $3,864,754$ & 0.200 & 0.400 & 0 & 1 \\
\hline feduc & Father's Education & $3,864,754$ & 3.642 & 2.191 & 0 & 8 \\
\hline \multicolumn{7}{|c|}{ Childbearing History of Mother } \\
\hline priorlive & Prior Births Now Living & $3,858,328$ & 1.135 & 1.298 & 0 & 23 \\
\hline priordead & Prior Births Now Dead & $3,855,605$ & 0.016 & 0.188 & 0 & 15 \\
\hline priorterm & Prior Other Terminations & $3,853,506$ & 0.422 & 0.886 & 0 & 28 \\
\hline \multicolumn{7}{|c|}{ Maternal Behaviors Before Pregnancy } \\
\hline cig_0 & $\begin{array}{l}\text { Cigarettes daily Before Pregnancy } \\
1 \text { if smoking before pregnancy, } 0\end{array}$ & $3,845,611$ & 1.176 & 4.841 & 0 & 98 \\
\hline smoker & otherwise & $3,864,754$ & 0.094 & 0.292 & 0 & 1 \\
\hline \multicolumn{7}{|c|}{ Maternal Factors/Choices During Pregnancy } \\
\hline & 1 if No Risk Factors Reported, 0 & & & & & 1 \\
\hline $\begin{array}{l}\text { no_risks } \\
\text { no_infec }\end{array}$ & $\begin{array}{l}\text { otherw1se } \\
1 \text { if No Infections Reported } 0 \text { otherwise }\end{array}$ & $\begin{array}{l}3,860,968 \\
3,854,655\end{array}$ & $\begin{array}{l}0.699 \\
0.973\end{array}$ & $\begin{array}{l}0.459 \\
0.163\end{array}$ & $\begin{array}{l}0 \\
0\end{array}$ & $\begin{array}{l}1 \\
1\end{array}$ \\
\hline precare & Month Prenatal Care Began & $3,766,014$ & 2.898 & 1.529 & 0 & 10 \\
\hline previs & Number of Prenatal Visits & $3,766,768$ & 11.290 & 4.198 & 0 & 98 \\
\hline pay_rec & Payment type & $3,864,754$ & 1.680 & 0.737 & 0 & 4 \\
\hline wic yes & 1 if recieving wic, 0 otherwise & $3,864,754$ & 0.376 & 0.484 & 0 & 1 \\
\hline \multicolumn{7}{|c|}{ Birth Outcomes of Pregnancy in 2017} \\
\hline dbwt & Birth Weight -- in Grams 0227-8165 & $3,861,721$ & 3262.134 & 592.202 & 227 & 8165 \\
\hline combgest & Combined Gestation -- in Weeks $17-47$ & $3,861,926$ & 38.602 & 2.487 & 17 & 47 \\
\hline sex_baby & 1 if Male, 0 if Female & $3,864,754$ & 0.512 & 0.500 & 0 & 1 \\
\hline
\end{tabular}

Source: National Natality Data Set 2016-17, NCHS (2018)

Marriage does not have a significant impact on birthweight among teenage mothers, which is in line with the reality that these are young mothers, often not planning to have a baby unlike older women. While age of mother does not significantly affect birthweight of baby in non-teen mothers, 
for each additional year of age, the children are marginally lighter among teenage mothers. This can be a result of the correlations between the age and level of education variables in our model.

Race and ethnicity play a pretty significant role for all mothers. White and Hispanic mothers have heavier babies than the other mothers (omitted category) but black mothers have babies that are almost 114 grams lighter in non-teen mothers and 137 grams lighter in teen mothers. That is almost a 3\% difference! Each additional year of education improves the birthweights of the children. Prior terminations have a bigger impact on teenage mothers as compared to non-teen mothers, even though the measured impact is extremely low.

Table 4. Base OLS Regression Models with Dependent Variable: Birthweight

\begin{tabular}{|c|c|c|c|c|c|c|c|c|c|}
\hline \multirow{2}{*}{$\begin{array}{l}\text { Dependent Var: } \\
\text { Birth Weight } \\
\text { (gms) }\end{array}$} & \multicolumn{3}{|c|}{ Model 1: All moms } & \multicolumn{3}{|c|}{$\begin{array}{c}\text { Model 2: Non-Teen } \\
\text { Moms }\end{array}$} & \multicolumn{3}{|c|}{ Model 3: Teen Moms } \\
\hline & Coefficient & t-stat & & Coefficient & t-stat & & Coefficient & t-stat & \\
\hline Constant & -4040.386 & -161.00 & & -4085.970 & -158.02 & & -3380.619 & -30.42 & \\
\hline combgest & 123.665 & 1117.80 & & 125.020 & 1090.80 & & 104.700 & 249.31 & \\
\hline sex_baby & 128.360 & 242.93 & & 129.537 & 238.51 & & 107.594 & 47.57 & \\
\hline foreigner & -23.905 & -14.37 & & -22.794 & -13.42 & & -51.088 & -6.31 & \\
\hline dmar & 15.278 & 21.55 & & 14.725 & 20.38 & & 7.353 & 1.89 & $*$ \\
\hline mager & -0.006 & -0.08 & $*$ & 0.032 & 0.46 & $*$ & -10.001 & -8.39 & \\
\hline mwhite & 28.925 & 24.74 & & 27.699 & 22.97 & & 17.481 & 3.49 & \\
\hline mblack & -113.728 & -81.91 & & -114.171 & -79.00 & & -137.229 & -25.84 & \\
\hline mhisp & 42.136 & 31.46 & & 42.624 & 30.62 & & 8.299 & 1.58 & \\
\hline meduc & 3.223 & 14.08 & & 3.157 & 13.63 & & 5.052 & 2.87 & \\
\hline fager & -0.400 & -1.81 & $*$ & -0.552 & -2.47 & & -1.003 & -0.66 & $*$ \\
\hline fwhite & 63.742 & 59.25 & & 67.548 & 60.84 & & 11.240 & 2.15 & \\
\hline fblack & 15.948 & 12.05 & & 19.875 & 14.45 & & -29.136 & -5.05 & \\
\hline fhisp & 31.682 & 25.45 & & 35.546 & 27.40 & & -8.617 & -1.61 & * \\
\hline feduc & 1.494 & 7.09 & & 1.477 & 6.92 & & 6.161 & 4.05 & \\
\hline m_ht_in & 30.053 & 78.01 & & 29.945 & 75.48 & & 33.407 & 19.60 & \\
\hline$\overline{b m i}$ & 12.896 & 29.23 & & 12.683 & 28.00 & & 19.419 & 9.37 & \\
\hline pwgt_r & -0.726 & -9.74 & & -0.687 & -8.97 & & -1.847 & -5.18 & \\
\hline priorlive & 33.634 & 141.51 & & 33.665 & 140.86 & & 36.612 & 13.85 & \\
\hline priordead & -17.328 & -12.38 & & -16.932 & -12.04 & & -27.833 & -1.81 & $*$ \\
\hline priorterm & -6.845 & -22.64 & & -6.652 & -21.87 & & -10.966 & -3.69 & \\
\hline precare & 18.008 & 97.39 & & 17.466 & 90.64 & & 24.503 & 37.66 & \\
\hline previsits & 8.263 & 117.29 & & 8.057 & 111.11 & & 11.632 & 39.28 & \\
\hline smoker & -90.411 & -63.12 & & -91.777 & -61.61 & & -57.365 & -11.02 & \\
\hline cig_0 & -2.756 & -33.32 & & -2.804 & -32.51 & & -1.868 & -6.49 & \\
\hline no_risks & 29.251 & 48.31 & & 27.711 & 45.03 & & 60.973 & 17.79 & \\
\hline no_infec & 21.697 & 13.56 & & 23.537 & 13.58 & & 11.788 & 2.86 & \\
\hline pay_rec & 13.172 & 32.75 & & 13.304 & 32.02 & & 8.568 & 5.39 & \\
\hline wic_yes & -6.596 & -9.97 & & -7.031 & -10.26 & & 5.788 & 2.26 & \\
\hline teenmom & -0.030 & -0.02 & $*$ & & & & & & \\
\hline teendad & -8.563 & -3.79 & & -14.788 & -3.59 & & 2.964 & 0.95 & $*$ \\
\hline Number of obs. & 3,17 & 351 & & 3,01 & 290 & & 165 & & \\
\hline
\end{tabular}

*Not statistically significant at 0.05 level

\section{Source: National Natality Data Set 2016-17, NCHS (2018)}

Prenatal care increases the birth outcomes for children of all types of mothers but has a clearly higher impact on teenage mothers' children. Smoking is correlated with a worse birth outcome for the infant, but surprisingly the impact is lower in teenage mothers as compared to non-teen mothers. This is probably because teenagers are less likely to smoke on a regular basis as compared to non- 
teenagers. Teenage mothers also show a better impact on their infants' birthweights due to the potential for lower risks to health. One of the most interesting results, that directly pertains to our policy angle is the access to WIC. Being enrolled in WIC has a negative impact on birthweights in non-teen mothers, while it has a positive impact on birthweights in teen mothers. It raises a question, that is beyond the scope of this paper, regarding whether access to WIC and similar programs increases the probability of teenage childbearing in the United States because of lowered personal opportunity costs.

Given that we have more than 3.8 million observations, it is not surprising that almost all the factors we identified in our simple OLS regression analysis were significant, due to the reduced internal threats to validity and avoidance of statistical errors such as multicollinearity and heteroskedasticity that would be a concern in smaller datasets. The R-squared values from all three models show that we can only determine about $35 \%$ of the variation in birthweights using these variables. The results of the logistical models estimated to test the determinants of teenage childbearing are shown in Table 5.

Model 5a refers to white mothers, Model 5b refers to black mothers, and Model 5c refers to Hispanic mothers in our dataset. The interpretation of Odds Ratios and their significance has to be done with care. The Odds Ratio (OR) is the ratio of the probability of being a teenmom to the probability of not being a teenmom in any given sample. For dichotomous independent variables, the Odds Ratio simply gives the difference between the two values of the dichotomous variable. For instance, the variable dmar has an odds ratio of 0.166 and a z-value of -142.75 in Model 5a. Thus, the odds that a married white woman is a teenage mother are lower by 0.166 than that of a nonmarried white woman being a teenage mother. The corresponding OR for black and Hispanic women show that being married decreases the odds by 0.106 for black women and 0.251 for Hispanic women. It is important to remember that teenagers are not necessarily thinking of getting married at that stage in their lives, however the results do show that being married lowers the odds of being a teenage mother, all else being held constant.

Table 5. Odds Ratios for Teenmom by Race/Ethnicity

\begin{tabular}{|c|c|c|c|c|c|c|c|}
\hline $\begin{array}{l}\text { Dependent Var: } \\
\text { Teenmom }\end{array}$ & \multicolumn{2}{|c|}{$\begin{array}{l}\text { Model 4a: white moms } \\
\text { Odds }\end{array}$} & \multicolumn{2}{|c|}{$\begin{array}{l}\text { Model 4b: black moms } \\
\text { Odds }\end{array}$} & \multicolumn{3}{|c|}{$\begin{array}{l}\text { Model 4c: Hispanic moms } \\
\text { Odds }\end{array}$} \\
\hline Constant & 1.584 & 17.72 & 2.148 & 26.47 & 0.693 & -12.99 & \\
\hline dmar & 0.166 & -142.75 & 0.106 & -63.72 & 0.251 & -92.54 & \\
\hline meduc & 0.430 & -176.51 & 0.424 & -124.16 & 0.632 & -88.89 & \\
\hline teendad & 31.326 & 195.44 & 31.212 & 130.16 & 41.013 & 187.77 & \\
\hline fwhite & 0.808 & -13.49 & 0.763 & -4.86 & 0.426 & -29.58 & \\
\hline fblack & 0.837 & -6.78 & 0.596 & -19.29 & 0.535 & -19.18 & \\
\hline fhisp & 0.875 & -5.73 & 0.908 & $-1.87 *$ & 0.406 & -55.76 & \\
\hline feduc & 0.899 & -23.87 & 0.957 & -5.51 & 1.001 & 0.27 & $*$ \\
\hline priorterm & 0.417 & -81.13 & 0.371 & -66.99 & 0.386 & -68.19 & \\
\hline smoker & 0.616 & -44.23 & 0.343 & -38.73 & 0.689 & -13.04 & \\
\hline no_risks & 2.299 & 65.75 & 2.629 & 58.94 & 2.876 & 70.74 & \\
\hline no_infec & 0.875 & -6.74 & 0.488 & -38.03 & 0.529 & -28.98 & \\
\hline $\begin{array}{l}\text { Number of obs. } \\
\text { Pseudo-R2 }\end{array}$ & & $\begin{array}{l}854,826 \\
0.407\end{array}$ & & $\begin{array}{l}34,062 \\
0.3321\end{array}$ & & $\begin{array}{l}80,681 \\
.3122\end{array}$ & \\
\hline
\end{tabular}

*Not statistically significant at 0.05 level

Source: National Natality Data Set 2016-17, NCHS (2018)

On the other hand, for continuous variables, such as education $(m e d u c)$, each additional category of education (ranging from 0 to 8 ) reduces the odds of being a teenage mother by 0.43 for white women, 0.42 for black women, and 0.65 for Hispanic women, all other characteristics being the same. Prior terminations of pregnancy also reduce the odds of being a teenage mother for all the 
three models. The race and ethnicity variables for fathers of the infants indicate that as compared to "unknown" or other fathers, the odds of a teenage mother go down for all three models. This can be taken to imply something more significant than it seems on the face value. The mothers that are unable or unwilling to give the information about the baby's father on the birth certificates are more likely to be teenagers than not. This implies that even during teenage years, girls in more stable relationships are less likely to become teenage mothers. Of course, part of this is speculation but part of it is because if the father's race and ethnicity and information are known, there is a lower probability of teenage childbearing.

On a lighter note, being a smoker reduces the odds of being a teenage mother as well based on the model results. However, to imply that it means that people should encourage teenagers to smoke would be a foolish conclusion to draw. Since the dataset heavily favors non-teen mothers, and only about $9 \%$ of all women were smokers prior to pregnancy based on the self-reported information, this result is not very meaningful in real terms. Having no health risks increases the OR for teenage pregnancy, which is not that surprising considering that teenagers tend to be healthier than older women in terms of having lower health risks to begin with.

The most crucial and sizeable impact on the OR is that of having a teendad! Assumedly, nonteenage women are not likely to date teenage boys. Therefore, "having a teen dad increases the probability of having a teen mom" does not necessarily need any data or analysis to state. However, the OR increases by 31 for white and black women, and a whole 41 for Hispanic women. This brings us back to the problem of teenagers in relationships resulting in teenage pregnancies and childbearing. Early sex education, continuing support, and access to birth control can help with reducing the incidence of teenage pregnancy in the United States even more.

\section{Conclusions and Implications for Texas Policy}

About 1.8 million out of the 3.8 million women in our dataset are non-Hispanic white, about 534,000 are non-Hispanic black, and about 680,000 are Hispanic. Like we saw in Table 2, the incidence of teenage pregnancy is much higher within black and Hispanic mothers, in terms of percentages. Policies that focus on the causes of racial and ethnic propensity towards early childbearing can help reduce some of the teenage childbearing issues as well.

On the whole, our results indicate that teenagers who become mothers have distinct characteristics, partner choices, maternal behaviors, and choices during and before pregnancy that play a crucial role in how their life shapes out to be. While the short-term impacts on the babies are not negative in terms of gestation and birthweight, the long-term impacts of children born to children must be studied more carefully. Policies that focus on addressable issues that can help to reduce the probabilities of teenage childbearing can be enforced at local, state, or national levels. While programs such as WIC and prenatal assistance for teenage and young mothers help them remain healthy and out of poverty, it is also important to try and identify if the availability of these options is not increasing the propensity for teenagers to have children earlier in life before they can personally provide for their families themselves.

The demographic breakout in Texas is different than the rest of the United States. In Texas the population is comprised of $43 \%$ white, $38 \%$ percent Hispanic, $12 \%$ black and the remaining are compromised of Asian, mixed, and other races. Compared to the demographic breakout within the United States of $62 \%$ percent white, $17 \%$ Hispanic and $13 \%$ black and the remaining are compromised of Asian, mixed, and other races. This type of demographic comparison can help policy makers in any state understand the audience and tailor policies to reduce the probability of teenage pregnancy. Our results show that black and Hispanic women have a 3-4\% higher probability of being a teenage mother as compared to the white women. Not only are black and Hispanic women more likely to become a teenage mother, they are more likely to have a lower birth weight child, as demonstrated in the literature review and from our dataset.

With these findings it is important that states are careful and design policies to directly target the black and Hispanic populations to reduce the probability of teenage childbearing. A 
recommendation could be a federally funded abstinence or safe-sex education program with added support in areas of higher concentration of black and Hispanic children that states can enforce differently based upon their own demographic compositions. For instance, this would require a state such as Texas to outline the goals and plans of how to prevent and reduce the number of teenage pregnancies, considering that white is the minority population in the state. Prior research done to prove the effectiveness of such policies (Horvath and Peters 1999; Ryan, Manlove \& Hofferth 2006) has mixed results, where only some research shows a significant relationship between nonmarital fertility and welfare agreements. Thus, states in the US should focus on the welfare policies and teen childbearing to enhance early prevention education.

\section{References}

Goldenberg, R. L., \& Culhane, J. F. 2007. "Low birth weigh in the United States." American Society for Nutrition. 85, pp. 584S-90S.

Horvath-Rose, A., \& Peters, H. Elizabeth. 1999. Welfare waivers and women's non-marital fertility decisions. ProQuest Dissertations Publishing.

Kaplan, G., Pamuk, E., Lynch, J., Cohen, R., \& Balfour, J. 1996. "Inequality in income and mortality in the United States: analysis of mortality and potential pathways." BMJ, 312, pp. 999-1003.

Klerman, L. 1993. "Adolescent pregnancy and parenting: contoversies of the past and lessons for the future." $J$ Adolesc Health 14, pp. 553-561.

Kost, K., Maddow-Zimet, I., \& Arpaia, A. 2017. Pregnancy, births and abortions among adolecents and young women in the United States, 2013: National and state trends by age, race and ethnicity. Guttmacher Institutue. Available at https://www.guttmacher.org/report/us-adolescent-pregnancy-trends-2013.

Males, M. 1995. "Adult involvement in teenage childbearing and STD.” Lancet 346, pp. 64-65.

Martin, J., Hamilton, B., Osterman, M., Driscoll, A., \& Drake, P. 2018. Births: Final data for 2016. Hyattsville: National Center for Health Statistics .

National Center for Health Statistics (NCHS). 2018, August 28. Vital Statistics Data Access. Retrieved from Centers for Disease Control and Prevention (CDC): https://www.cdc.gov/nchs/data_access/vitalstatsonline.htm.

Office of Adolescent Health. 2017, February 17. Pregnancy Assitance Fund. Retrieved June 10, 2018 , from U.S. Department of Health and Human Serices: https://www.hhs.gov/ash/oah/grant-programs/pregnancy-assistancefund/index.html.

Parnell, K., Sargent, R., Thompson, S., Duhe, S., Valois, R., \& Kember, R. 1996. "Black and white adolescent females' perceptions of ideal body size." J Sch. Health 66 (3): 112-118.

Roth, J., Hendrickson, J., Schilling, M., \& Stowell, D. W. 1998. "The Risk of Teen Mothers Having Low Birth Weight Babies: Implications of Recent Medical Research for School Health Personnel." Journal of School Healh 68 (7): 271-275.

Ryan, S., Manlove, J., \& Hofferth, S. 2006. "State-level Welfare Policies and Nonmarital Subsequent Childbearing." Population Research and Policy Review 25(1): 103-126.

Santelli, J., Lindberg, L., Finer, L., \& Singh, S. 2007. "Explaining recent declines in adolescent pregnancy in the United States: The contribution of abstinence and improved contraceptive use." American Journal of Public Health 97 (1): 150-156.

Scholl, T., Hediger, M., \& Belsky, D. 1993. "Prenatal care and maternal health during adolescent pregnancy: a review and meta-analysis." J Adolesc Health 15, pp. 444-456.

Ventura, S., Martin, J., Matthews, T., \& Clarke, S. 1996, June. “Advance report of final natality statistics, 1994.” Vital Health Stat 11(1): 1-86. 